\title{
Globalization and Social Quality
}

\author{
Mária Antalován ${ }^{1, *}$ \\ ${ }^{1}$ Department of Social Development and Labor, Faculty of National Economy, University of \\ Economics in Bratislava, Slovak Republic
}

\begin{abstract}
On 1 March 2017, the European Commission presented a White Paper on the future of Europe emphasizing the phenomenon of globalization. Its aim is to assess what globalization means and will mean to the EU. In 2000, the social quality became a strategy for the EU's economic policy. It is long known that both phenomena bring with them a number of changes of positive and negative sense. We see them as processes that deeply affect the existing structures of each country. For this reason, we have set the aim of our paper to evaluate the existing situation in globalization as well as in the social quality in Slovakia and in the V4 countries and also to clarify the interconnection between the two important phenomena. Analysis is based on an innovated globalization index that can be mapped in three dimensions: economic, social and political. In the social quality research, we take into account created index of the social quality at our department. Using the data obtained, we assess the interconnection of manifestations of globalization and the social quality as well as the three dimensions of globalization with the conditional factors of social quality and consider their existing interdependence.
\end{abstract}

\section{Introduction}

In our paper, we focus on two important phenomena that are currently culminating and bringing both positive and negative consequences. These are globalization and the social quality. There has been a great interest in the literature to explore primarily globalization $[2,5-32 ; 1,767-845]$ and its influence on economic growth. There exist the extensive studies on it in theoretical, methodological and empirical level. From authors we note as example K. Morvay, J. Kotěšocová, J. J. Mihola, J. P. Wawrosz [3] and F Domonkos, F. Ostrihoň [4] and others. The socio-economic experts has been dealt less with the social quality. It was paid to the attention by W. Beck and L. J. Maesen and A. Walker in 1997, with their book The Social Quality of Europe. Three years later, their concept became part of the European Economic Policy [Amsterdam Declaration on the Social Quality, 1997]. By its nature, it represents a new perspective for the perception of not only the social but also the economic, political, ecological and cultural dimensions of human existence. It is still unknown in Slovakia. For this reason, we set up to examine the development of globalization and the social quality in Slovakia and also to determine their stage of implementation within the V4 countries, but above all to verify their interdependence.

\footnotetext{
*Corresponding author: maria.antalova@euba.sk
} 


\section{Theoretical Approaches to Research}

\subsection{Approaches to Globalization}

Globalization is a new phenomenon of the $20^{\text {th }}$ century (Europe 2020), which researchers are dealing with from different scientific disciplines, not only in terms of economics and finance [6], but also politics, culture, environment, psychology, social psychology, and so on. [7]. In spite of all their efforts, its identification remains inconsistent and for its global character, on a high level of abstraction, which causes the different approaches to its operationalization and quantification [8].

As an example, we summarize the statements in which globalization is considered as:

1. the act or process of globalization,

2. the state of being globalized,

3. the development of an increasingly integrated global economy marked especially by free trade,

4. free flow of capital and the tapping of cheaper foreign labor markets.

Experts in the OECD regard globalization as "... the process by which markets and production are becoming more dependent in different countries for the dynamics of commodity, services and mobility of capital and technology" [9].

For our research base, we have chosen definition from various authors. They are A. Dreher [10], which is based on W. C. Clark [11] and P. Norris [12] and T. Levitt [13], also N. Coe [14] in which "globalization describes the process of creating networks of connections among actors at intra-or multi-continental distances, mediated through a variety of flows including people, information and ideas, capital and goods. Globalization is a process that erodes national boundaries, integrates national economies, cultures, technologies and governance, and produces complex relations of mutual interdependence". In this definition is globalization perceived as a process leading to integration not only in economic but also in social area $[11,15]$. We draw attention to its overall manifestation, it means to its economic, social and political implications, and focus on its connection to the social quality.

\subsection{Social Quality Phenomenon}

The authors of the social quality (W. A. Beck, L. J. G. van der Maesen, A. Walker) defined it as "the extent to which people are able to participate in the social, economic and cultural life of their communities and develop their well-being, capacity and individual potential" $[16,6]$. On its abstract level, it represents a wide phenomenon's continuum, which is possible, according to the authors, divided into three types of factors: conditional, constitutional, and normative. They play a key role in the identification, quantification and interpretation of the social quality. In our paper, for the broadness of the issue, we will focus only on its conditional factors.

The social quality, at level of the conditional factors, consists of 4 main components: socio-economic security, social inclusion, social cohesion and social empowerment.

Socio-economic security is based on existential security (income, social protection, health care), which should be guaranteed by the state. People should not feel social inclusion and a minimum level of social exclusion. Exclusion can be considered at a general level as a rejection or ignoring social rights. Social cohesion refers to the coherence between the different communities in society. It is an indispensable element of social development, as well as individual self-realization. People must be prepared to fully cope with the rapid and significant socio-economic changes. Social empowerment means enabling them to control their own lives and to respond to opportunities and options. Modern democratic societies do not need strong leadership but must be able to create the 
conditions for enhancing capability of citizens. According to P. Herrmann, there are different forms of the social empowerment: political, economic, socio-psychological, information and the social mobility skills. At the personal level, empowerment represents the full range of knowledge, skills and experiences that lead to self-esteem, selfdevelopment, and self-affirmation [17].

\section{Methods and Quantification}

In examining of globalization, we will came out from quantifier the KOF index, which is written by A. Dreher. The index was first published in 2002, later edited in 2007 [10] and most recently in 2017. From the point of extension of the whole issue, we draw attention to the synthetic index of globalization, which includes the values of economic, political and social globalization.

In case of the social quality, start point of our research is dissertation of A. Chinoracka with title Social Quality and its determinants [19]. We worked with statistical data from Eurostat, EU SILC, Economist Intelligence Unit, and Transparency International. In particular, we used following Eurostat's databases: Population and social conditions, transport, Environment and energy. Eurostat also offers data on European Union policies from which we analyzed: Sustainable Development Indicators, Employment and Social Policy Indicators, Quality of life. The databases also contain EU SILC (EU-Statistics on Income and Living Conditions) surveys, which we also used in our research.

For 2011 year, we had possibility to have full information, so we decided to analyze the social quality in that period. We all consider it unique, relevant and equally important for the social quality research. For the validity of individual indicators, we used a test that verified their validity (Kaiser-Meyer-Olkin rate).

We used Factor Analysis with purpose to obtain the factor burden of indicators in individual dimensions of the social quality. We have standardized data from various types of databases to obtain their validity and reliability by transforming them into Z-scores. We tested whether it is appropriate to use factor analysis using the Kaiser-Meyer-Olkin (KMO) test. Based on its results, we reduced the existing 41 indicators to 15 in order to simplify the creation of the social quality index. Factor burdens played a key role and were used as weights of individual indicators of the socio-economic security, the social inclusion, the social cohesion and the social empowerment and entered into the construction of subindexes of the social quality.

Index Creation: we used a subjective method of determining the average of values of the individual components. We placed the same weights on all components, i.e. we considered them equal in terms of their impact on a particular conditional factor of the social quality. We have added and divided all component values by the number of components. By this way was created an average value that allowed us to determine the level of implementation and at the same time provided the opportunity to compare Slovakia with other EU countries. The used formulas we do not mention for the wide scope of issue.

Creation of Synthetic Index of Social Quality - was done by a subjective way - by calculating average values. We assumed the equality of all partial indicators. It is a calculation of the social quality index based on the average of values of the partial indicators (sub-indexes of conditional factors of social quality) and then dividing by the appropriate number (in our case the value 4).

\section{Empirical Findings and Discussion}

We focused the empirical analysis on several circuits, which served as the basis for hypothesis. We paid attention to the following realities: 
1. To analyze evolution of globalization in V4 countries during period of years 2007 -2016 with using new innovated form of globalization index.

2. To compare phenomenon of the social quality in the V4 countries with purpose to identificate its level in Slovakia,

3. To explore interconnectedness between globalization and the social quality in total form, but also in their special dimensions.

In our research, we focused on both phenomena only in 2011, because we were limited by the social quality database.

\subsection{Evolutionary Tendencies in Globalization}

Tendency in evolution of globalization of V4 Countries we analyzed through new innovated Globalization Index, according to which we can note, that the highest level of globalization was achieved by Hungary.

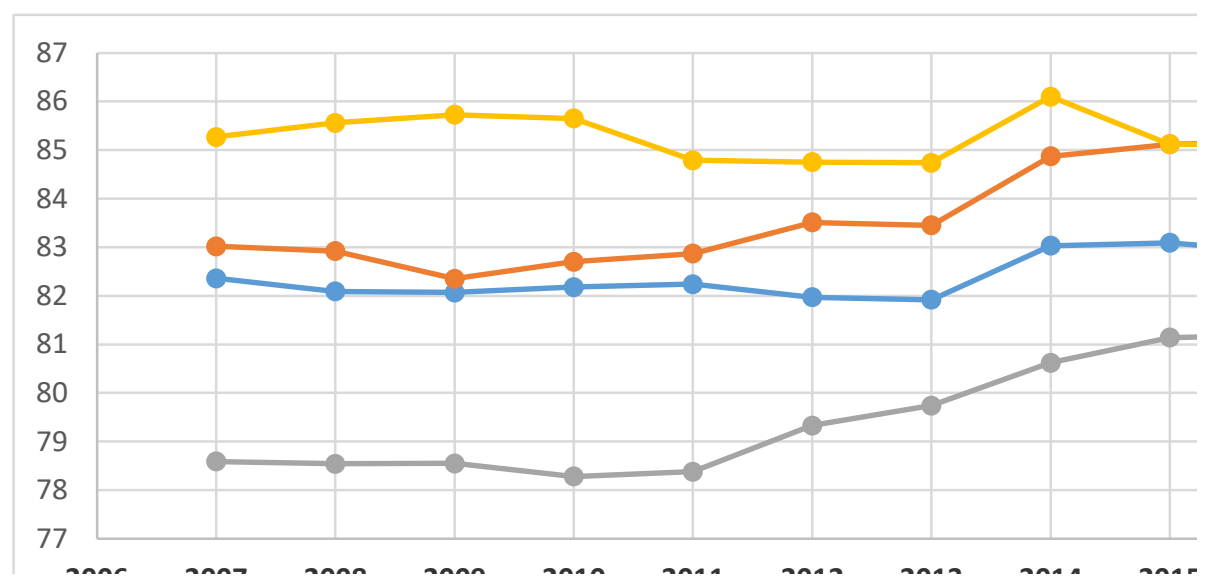

Fig 1. Globalization in V4 Countries in 2007 - 2016

In all the monitored years, except for 2016, this country reached the highest values of the globalization index, with an average value of 85.284. The Czech Republic achieved the second highest value with an average of 83.6. Slovakia ranked 3rd in the trend $(82,384)$. Poland with the lowest average index of 79.439 took the last place.

The highest level of development process over the reference period in 2007-2016 was achieved by Poland, KOF index increased from value 78,59 to 81,2 (2,61 points). The second ranked the Czech Republic with difference by 1,87 points of index value. Slovakia recorded an increase only 0,53 points. Last place in order was occupied by Hungary. Difference between value of index in year 2007 and 2016 was -0,14. It means here was decreasing form of evolution.

\subsection{Comparison of Social Quality in V4 Countries}

Table 2 shows the level of the Global Social Quality Index as well as its individual subindexes (Socio-economic security, Social inclusion, Social cohesion, and Social empowerment) in the V4 countries in 2011. Based on the data, we can conclude different levels of the social quality implementation. 
Table 2. Conditional Factors in V4 Countries

\begin{tabular}{|l|r|r|r|r|}
\hline Conditional Factor & Slovakia & Czech Republic & Poland & Hungary \\
\hline Socio-economic Security & $-0,7$ & $-0,56$ & $-0,7$ & $-0,12$ \\
\hline Social Inclusion & $-0,51$ & $-0,53$ & 0,4 & 0,75 \\
\hline Social Cohesion & 0,38 & $-0,05$ & $-0,2$ & 0,67 \\
\hline Social Empowerment & $-1,07$ & 0,1 & 0,07 & $-0,17$ \\
\hline Social Quality & $\mathbf{0 , 1 3}$ & $\mathbf{0 , 2 9}$ & $\mathbf{0 , 0 4}$ & $\mathbf{- 0 , 0 3}$ \\
\hline
\end{tabular}

The highest level is found in the Czech Republic, which reached the value of the index of the social quality 0.29 . It is followed by Slovakia (0.13) with an index value 16 points lower than in the Czech Republic. Poland has only 0.04 index value and Hungary has the lowest level with negative value of index -0.03 .

Table 2 presents values of the socio-economic security index. Its higher value means the lower level of implementation. Slovakia and Poland ranked first in the implementation of the socio-economic security ( -0.7 sub-index). Second place goes to the Czech Republic with a sub-index value of -0.56 , followed by Hungary with a sub-index value of -0.12 .

The social inclusion means the ability of individuals to integrate into society through work, as well as the ability to procure sufficient financial resources to ensure decent living conditions, based on unjustified income inequalities. Table 2 also shows the values of the social inclusion sub-indexes. Here, too, as in the case of the socio-economic security, countries achieved high values, it means that they are on the worst level of implementation, while low-value countries represent the best level. The Czech Republic ranked first with a sub-index value of -0.53 . It is followed by Slovakia with a value of -0.51 . The third place is Poland (0.4) and the last place is Hungary (0.75).

The social cohesion reflects social establishment in the country, determined by the political environment, culture, corruption, as well as the possibilities of the modern communication technologies for example as is the Internet. If here exists higher value of sub-index, it means the higher level of the social quality implementation. Hungary leads the social cohesion of all 4 countries surveyed, ranked first. In second place is Slovakia, third the Czech Republic and last Poland.

The human capital, investment in education, development of capabilities are the basis of the social empowerment. Sub-index, which is presented provides an overview of the social quality implementation. Here too, the higher of value means the higher level of the social quality implementation. The Czech Republic was leader in the social empowerment with a sub-index value of 0.1 . This is followed by Poland (0.07), Hungary $(-0.17)$ and Slovakia with the sub-index of -1.07. It occupied the penultimate place within the EU countries.

\subsection{Relations between Globalization and Social Quality}

Correlation analysis between globalization and the social quality is the last partial goal of our paper. We have applied the correlation analysis to the V4 countries and we examined the interconnections between them in 2011 year.

We have verified the following hypotheses:

1. The phenomenon of globalization and the social quality are closely related, and on basis of this fact, we can expect, that with increasing of the one level will also increase level of second. 
2. There exist also relations between partial dimensions of globalization as well as the social quality. In confirming of our assumption, we can expect that by raising its level we will achieve positive changes also in every conditional factors.

Hypothesis 1: Our assumption, that the phenomenon of globalization and the social quality in their global form are strongly related to one another, did not confirmed us, because the intensity of both phenomena is very low, value of Pearson's coefficient of correlation was only 0,017449751 . However, we can argue, that level of implementation globalization and level of implementation of some conditional factors of the social quality are related. We discovered the most significant relations between: social cohesion and globalization $(0,808011063)$ and socio-economic security and globalization $(0,763949742)$, but also between the social quality and the social globalization $(0,689827735)$.

Table 3. Correlation Analysis

\begin{tabular}{|l|r|}
\hline \multicolumn{1}{|c|}{ Variables Relation } & \multicolumn{1}{c|}{ Correlation } \\
\hline Globalization/Social Quality & 0,017449751 \\
\hline Globalization/Socio-economic Security & 0,763949742 \\
\hline Globalization/Social Inclusion & 0,013409011 \\
\hline Globalization/Social Cohesion & 0,808011063 \\
\hline Globalization/Social Empowerment & $-0,188653081$ \\
\hline Social Quality/Economic Globalization & $-0,2025377$ \\
\hline Social Quality/Social Globalization & 0,689827735 \\
\hline Social Quality/Political Globalization & $-0,614286345$ \\
\hline Socio-economic Security/Economic Globalization & 0,91532128 \\
\hline Social Inclusion/Economic Globalization & 0,527037826 \\
\hline Social Cohesion/Economic Globalization & 0,417977839 \\
\hline Social Empowerment/Economic Globalization & 0,558477048 \\
\hline Socio-economic Security/Social Globalization & $-0,255486568$ \\
\hline Social Inclusion/Social Globalization & 0,259667353 \\
\hline Social Cohesion/Social Globalization & 0,259667353 \\
\hline Social Empowerment/Social Globalization & $-0,54598875$ \\
\hline Socio-economic Security/Political Globalization & 0,577346663 \\
\hline Social Inclusion/Political Globalization & 0,905784083 \\
\hline Social Cohesion/Political Globalization & $-0,006574986$ \\
\hline Social Empowerment/Political Globalization & 0,747913331 \\
\hline
\end{tabular}

Hypothesis 2: There exist relations between partial dimensions of globalization as well as dimensions of the social quality, which has been partially confirmed. Table 3 Correlation analysis shows the Pearson coefficient, which values ranged in interval from 0,006574986 to 0,91532128 .

The following observations can be made: 
1.The strongest relationship has been demonstrated between dimensions:

- the socio-economic security and the economic globalization $(0,91532128)$,

- the social inclusion and the political globalization $(0,905784083)$,

- the social empowerment and the political globalization $(0,747913331)$.

2.We have noted a medium intensity relationship between:

- the socio-economic security as and the political globalization $(0,577346663)$,

- the social empowerment and the social globalization (-0.54598875),

- the social empowerment and the economic globalization $(0,558477048)$,

- the social inclusion and economic globalization (0,527037826).

\section{Conclusion}

In our research, we set up the goal to analyze of manifestation of two important phenomena of globalization and the social quality. We have defined these phenomena and selected the approach to their quantification. We identified level of the social quality implementation in Slovakia and compared it with V4 countries. By correlation analysis, we came to the following general conclusions:

1. Globalization and the social quality are two separated processes and relationship between them has not been manifested in global form. But we note the most intense relationship between one global phenomenon and some dimensions of second phenomenon. We discovered strong relations between globalization and socio-economic security as conditional factor of the social quality and the social quality and social globalization.

2. We discovered also significant interconnection between some dimensions of globalization and some dimensions of the social quality, which can be important in the implementation process. We can deduct, that the political and economic globalization can influence at process of implementation of the socio-economic security, the social inclusion and the social empowerment of conditional factors of the social quality. We recommend applying our current findings in the new strategy of the economic policy.

Writing this paper was supported by the project VEGA no. 1/0251/19 "Housing Investment in Households and the Possibility of Their Alternative Using as an Additional Income at the Time of Receiving the Pension Benefit".

\section{References}

1. K. Morvay et al. Economic Development of Slovakia in 2012 and Outlook up to 2014. Ekonomický časopis, 61, 767-845 (2013)

2. K. Morvay. Stratégia a priebeh ekonomickej transformácie na Slovensku. Ekonomický časopis, 53, 5-32 (2005)

3. J. Kotěšovcová, J. J. Mihola, J. P. Wawrosz. The Complex Typology of the Relationship between GDP and Its Sources. Ekonomický časopis, 65, 935-951 (2017)

4. F. Domonkos, F. Ostrihoň, Inclusive Growth in Selected Central European Countries. Ekonomický časopis, 63, 881-905 (2015)

5. Európa 2020. Sumár Stratégie Európa 2020. Available: http://ec.europa.eu/europe2020/europe-2020-in-a-nutshell/index_sk.htm.

6. F. Broner, J. Ventura. Rethinking the Effects of Financial Globalization. The Quarterly Journal of Economics, 131, 1497-1542 (2016)

7. M. Šikula. K metodologickým východiskám ponímania fenoménu globalizácie. Ekonomický časopis, 53, 663-679 (2005) 
8. V. Jeníček, (2002). Globalizace světového hospodářství. (Praha: C. H. Beck, 2002)

9. Measuring Globalization. OECD Handbook on Economic Globalization Indicators. OECD (2005)

10. A. Dreher, Does globalization affect growth? Evidence from a new index of globalization. Applied Economics, 38, 1091-1110 (2006)

11. W. C. Clark. Governance in a Globalizing World, Environmental Globalization, (Brooking Institution Press, 2000)

12. P. Norris. Governance in a Globalizing World, Global Governance and Cosmopolitan Citizens, 155-177. (Brookings Institution's Press, 2000)

13. T. Levitt. Globalization of Markets. Harvard Business Review, 61, 92-102 (1983)

14. N. Coe. The Internationalization/Globalization of Retailing: Towards an EconomicGeographical Research Agenda. Environment and Planning A, 36, 1571-1594 (2004)

15. F. Križan, K. Bilková, P. Kita, T. Siviček. Transformation of Retailing in PostCommunist Slovakia in the Context of Globalization. Economics and Management. 19, 148-163 (2016)

16. W. A. Beck, L. J. G. van der Maesen, A. S. Walker. Social Quality: A Vision for Europe. Studies in Employment and Social Policy. (Hague/London/Boston: Kluwer Law International, 2001)

17. P. Herrmann. Empowerment: The core of Social Quality. European Journal of Social Quality. 5, 292-302 (2006)

18. A. Dreher, N. Gaston, P. Martens. Measuring Globalization: Gauging its Consequences. New York: Springer (2008)

19. A. Chinoracká. Social Quality and its Determinants. Dissertation. Department of Social Development and Labor, Faculty of National Economy, University of Economics in Bratislava (2015)

20. https://kof.ethz.ch/en/forecasts-and-indicators/indicators/kof-globalisation-index.html 